\title{
Predictive value of transcranial doppler ultrasound for cerebral small vessel disease in elderly patients
}

\author{
Valor preditivo do ultrassom doppler transcraniano para doença de pequenos vasos em \\ pacientes idosos
}

Shengqi $F U^{1}$, Jiewen ZHANG², Hongtao ZHANG', Shuling ZHANG ${ }^{1}$

\begin{abstract}
Objective: To investigate the predictive value of transcranial Doppler (TCD) ultrasound for cerebral small vessel disease in elderly patients. Methods: Transcranial Doppler ultrasound and magnetic resonance imaging (MRI) were performed on 184 elderly patients with cerebral small vessel disease. The relationship of clinical characteristics and TCD ultrasound parameters with severe white matter lesions (WMLs) in MRI were investigated by univariate analysis and multivariate analysis. Results: The univariate analysis showed that age, left middle cerebral artery (MCA) mean flow velocity, right MCA mean flow velocity and mean MCA pulsatility index were significantly correlated with severe WMLs $(p<0.05)$. The multivariate logistic regression analysis showed that only age (odds ratio: 1.21; 95\% Cl: 1.10-1.36; $p<0.01$ ) and MCA pulsatility index (dominance ratio: 1.13;95\% Cl: 1.06-1.80; $p=0.02$ ) were significantly correlated with severe WMLs. The analysis of TCD ultrasound parameters showed that when the cut-off for MCA pulsatility index was 1.04, it could identify severe WMLs. The area under the curve was 0.70 ( $95 \% \mathrm{Cl}: 0.60-0.80)$. The sensitivity and specificity were $63.0 \%$ and $72.0 \%$, respectively. The positive and negative predictive values were $35.4 \%$ and $86.6 \%$, respectively. Conclusion: The MCA pulsatility index in TCD ultrasound is significantly correlated with severe WMLs; and TCD ultrasound can guide selective MRI for the detection of WMLs.
\end{abstract}

Keywords: Cerebral small vessel disease; ultrasonography, transcranial doppler.

\section{RESUMO}

Objetivo: Investigar o valor preditivo do ultrassom de Doppler transcraniano (TCD) para doença de pequenos vasos (SVD) em pacientes idosos. Métodos: ultrassonografia de TCD e ressonância magnética (RM) foram realizadas em 184 idosos portadores de SVD cerebral. As relações das características clínicas e os parâmetros ultrassonográficos do TCD com lesão grave de substância branca (WML) no desempenho da RM foram investigados por análise univariada e análise multivariada. Resultados: A análise univariada mostrou que, a idade, a velocidade média de fluxo (MFV) da artéria média cerebral (MCA) esquerda, a MFV da MCA direita e o índice de pulsatilidade (PI) médio estiveram significativamente relacionados à WML grave $(P<0,05)$. A análise de regressão logística multivariada mostrou que apenas a idade (razão de chances: 1,21; IC95\%: 1,10-1,36; P <0,01) e o PI da MCA (razão de dominância: 1,13; IC 95\%: 1,06-1,80; P = 0,02) estiveram significativamente relacionados a WML grave. A análise dos parâmetros ultrassonográficos do TCD mostrou que, quando o ponto de corte do IP do MCA foi 1,04, ele pôde identificar à WML grave. A área sob a curva foi de 0,70 (IC 95\%: 0,60-0,80). A sensibilidade e especificidade foram de 63,0\% e $72,0 \%$, respectivamente. Os valores preditivos positivos e negativos foram de 35,4\% e 86,6\%, respectivamente. Conclusão: O PI da MCA na ultrassonografia do TCD está significativamente relacionado à WML grave. A ultrassonografia TCD pode orientar a ressonância magnética seletiva para detecção da WML.

Palavras-chave: Doenças de pequenos vasos cerebrais; ultrassonografia Doppler transcraniano.

Cerebral small vessel disease is one of the causes of ischemic stroke ${ }^{1}$. Cerebral small vessel disease has been found to be correlated with diseases including stroke ${ }^{2}$, cognitive and affective disorder ${ }^{3}$, dementia ${ }^{4}$, and gait dysfunction ${ }^{5}$.

\footnotetext{
'Zhengzhou People's Hospital, Department of Neurology, Zhengzhou, China;

${ }^{2}$ Zhengzhou University, People's Hospital, Department of Neurology, Zhengzhou, China

Shengqi Fu iD https://orcid.org/0000-0003-3335-6102; Jiewen Zhang iD https://orcid.org/0000-0001-5355-3256; Hongtao Zhang iD https://orcid.org/0000-0003-0348-6520; Shuling Zhang (iD) https://orcid.org/0000-0003-1357-5578

Correspondence: Jiewen Zhang; Department of Neurology, People's Hospital, Zhengzhou University, 7 Weiwu Road, Zhengzhou 450003, China; E-mail:jwz6363154@126.com

Conflict of interest: There is no conflict of interest to declare.

Support: Science and Technology Project of Zhengzhou City (No. 20140462).

Received 05 May 2018; Received in final form 08 November 2018; Accepted 20 January 2019.
} 
These correlations are especially notable for cognitive disorder and dementia. Magnetic resonance imaging (MRI) is often used for diagnosis of cerebral small vessel disease ${ }^{6-8}$. Cerebral white matter lesions (WMLs), lacunar infarction and microhemorrhage are the main MRI indications of cerebral small vessel disease $e^{9,10,11}$. However, the expense of MRI in screening the subclinical lesions of patients is high. Transcranial Doppler (TCD) ultrasound, with related imaging technology, is an inexpensive and noninvasive examination method for detection of cerebral lesions. At present, it has the most significant clinical application value in the diagnosis of subarachnoid hemorrhage and intracranial vascular spasm caused by aneurysm rupture ${ }^{12,13}$. In addition, TCD ultrasound can effectively assess the cerebral blood flow velocity of intracranial blood vessels in patients with sickle cell disease, stroke or brain death ${ }^{14}$. The pulsatility index, a parameter of TCD ultrasound, has been used for many years to reflect the resistance of small vessels ${ }^{15,16,17}$. This study aimed to investigate the relationship between the pulsatility index in TCD ultrasound and cerebral small vessel disease in elderly patients.

\section{METHODS}

\section{Participants}

One hundred and eighty-four elderly patients who participated in the aging study at the Zhengzhou People's Hospital from November 2011 to September 2014 were enrolled in this study. The inclusion criteria were as follows: 1) the clinical and imaging findings of the patients met the diagnostic criteria of the Chinese Expert Consensus on the Diagnosis and Treatment of Cerebral small vessel disease $^{18}$ (e.g., arteriosclerosis, cerebral amyloid vessels, focal demyelination of white matter, etc.); 2) the imaging findings showed lacunar cerebral infarction, leukoaraiosis, cerebral microhemorrhage or perivascular space enlargement; 3 ) the age of patients was 60-85 years. The exclusion criteria were as follows: 1 ) patients who had a contraindication for MRI evaluation; 2) patients with a history of atrial fibrillation; 3) a carotid ultrasound showed the presence of carotid artery stenosis; 4) magnetic resonance angiography or conventional TCD ultrasound showed obvious stenosis or occlusion of great vessels near the circle of Willis; 5) patients who had an absent temporal window or a poor temporal window; 6) continuous TCD ultrasound monitoring showed the presence of microembolic signs. This study was approved by the ethics committee of the Zhengzhou People's Hospital. Written informed consent was obtained from all participants.

\section{TCD ultrasound}

Transcranial Doppler ultrasound was performed on the day of the patient's visit using a Dop-X4 TCD
(Compumedics Germany GmbH, Singen, Germany). The patient lay in the supine position and kept calm. The $2-\mathrm{MHz}$ pulse probe was placed at the temporal window to detect the middle cerebral artery (MCA), with a depth of $60 \mathrm{~mm}$. The TCD ultrasound parameters, including peak systolic velocity, end diastolic velocity, mean flow velocity and pulsatility index were recorded. The MCA pulsatility index was automatically generated based on the calculation formula: (peak systolic velocity - end diastolic velocity) $\div$ mean flow velocity; and the mean value of the bilateral MCA pulsatility index was obtained.

\section{MRI inspection}

The MRI skull inspection was performed on the day of the visit using a 3.0T MRI scanner (GE Healthcare, WI, USA). The inspection items included T1-weighted image, T2-weighted image and gradient echo sequence (T2*). White matter lesions were quantitatively calculated by using the fluid-attenuated inversion recovery (FLAIR) 9.0 software. The severity of WMLs were graded using Fazekas scale (Fazekas score 0-2 points: without severe WMLs; Fazekas score 3-6 points: with severe WMLs) ${ }^{19}$. A lacunar infarction was defined by a T1-weighted image with a 3-15 mm low-density lesion and a FLAIR high-signal change. A microhemorrhage was defined by $\mathrm{T} 2 *$ sequence with a 2-10 mm circular region of hemorrhagic signal. The MRI results were analyzed by a trained neurology specialist who was unaware of the TCD ultrasound results. The scores of age-related WMLs, lacunar infarction and microhemorrhage were 0.91 (95\%CI: 0.82-0.97), 0.88 (95\%CI: 0.72-0.95) and 0.93 (95\%CI: 0.85-0.98), respectively.

\section{Collection of general data}

The general data of participants were collected on the day of the visit, and included gender, age and history, including stroke, coronary heart disease, diabetes mellitus, hypertension, dementia and hyperlipidemia, etc.

\section{Detection of blood biochemical indexes}

Ten milliliters of elbow vein blood were taken from the participants at admission or on the morning of the second day. The blood biochemical indexes including total cholesterol, triglycerides, low-density lipoprotein cholesterol, high-density lipoprotein cholesterol, blood glucose and glycosylated hemoglobin were detected and analyzed using a type-1747 automatic biochemical analyzer (Hitachi High-Technologies Corp., Tokyo, Japan).

\section{Statistical analysis}

Statistical analysis was carried out using SPSS17.0 software (SPSS Inc., Chicago, IL, USA). The relationships of clinical characteristics and TCD ultrasound parameters with severe WMLs found in MRI evaluation were investigated by univariate analysis. The enumeration data were presented as 
number and rate, and the comparison between two groups (with severe WMLs and without severe WMLs) was performed using the $\chi^{2}$ test. The measurement data were presented as mean $\pm \mathrm{SD}$, and the comparison between two groups was performed using the t-test. A multivariate logistic regression analysis was performed to identify the independent risk factors for severe WMLs. The $p$ value $<0.05$ was considered as statistically significant.

\section{RESULTS}

\section{General information of patients}

Of the 184 patients, there were $88(47.8 \%)$ males and $96(52.2 \%)$ females. The average age was $68.2 \pm 7.3$ years. There was a history of stroke in 20 (10.9\%) patients, coronary heart disease in 35 (19.0\%) patients, diabetes mellitus in $33(17.9 \%)$ patients, hypertension in $139(75.5 \%)$ patients, dementia in $5(2.7 \%)$ patients and hyperlipidemia in 65 $(35.3 \%)$ patients. Systolic pressure was $152.61 \pm 25.15$ and diastolic pressure was $76.56 \pm 15.52 \mathrm{mmHg}$. The total cholesterol, triglycerides, high-density lipoprotein cholesterol, low-density lipoprotein cholesterol, blood glucose and glycosylated hemoglobin were $5.27 \pm 1.44,1.56 \pm 0.23,1.18 \pm 0.04$, $3.33 \pm 1.21,5.43 \pm 0.79$ and $5.46 \pm 1.01 \mathrm{mmol} / \mathrm{L}$, respectively. The MCA pulsatility index was $0.97 \pm 0.43(\mathrm{~cm} / \mathrm{s})$. The WML volume was $2.60 \pm 0.56 \mathrm{~cm}^{3}$. According to the age-related white matter changes scale, the scores of the WMLs were $4.43 \pm 0.68$ points. According to the Fazekas scale, there were $29(15.8 \%)$ with a score of $0 ; 56(30.4 \%)$ with a score of 1; $63(34.2 \%)$ with a score of 2 and $36(19.6 \%)$ patients with a score of 3 points; in other words, there were 36 patients with severe WMLs and 148 patients without severe WMLs. There were 124 (67.4\%), 37 (20.1\%) and 23 (12.5\%) patients with 1, 2 and 3 lacunar infarctions, respectively, and there were 172 (93.5\%), 7 (3.9\%) and 5 (2.9\%) patients with 1, 2 and 3 microhemorrhages, respectively.

\section{Comparison of clinical and TCD ultrasound parameters between patients with and without severe WMLs}

According to the WML quartile scores on the Fazekas scale, 184 patients were divided into two groups; those with, and those without severe WMLs. The univariate analysis showed that the age of patients with severe WMLs was significantly higher than that of patients without severe WMLs $(\mathrm{p}<0.01)$. The left MCA mean flow velocity and right MCA mean flow velocity in patients with severe WMLs were significantly lower than those in patients without severe WMLs, respectively ( $\mathrm{p}<0.01 ; \mathrm{p}<0.05$ ). The mean MCA pulsatility index in patients with severe WMLs was significantly higher than those in patients without severe WMLs $(\mathrm{p}<0.01)$. There was no significant difference of any other index between the two groups ( $\mathrm{p}>0.05)$ (Table).

Table. Comparison of clinical and transcranial Doppler ultrasound parameters between patients with and without severe WMLs.

\begin{tabular}{|c|c|c|c|}
\hline Index & With severe WMLs $(n=36)$ & Without severe WMLs $(n=148)$ & $\mathrm{p}$ \\
\hline Age (years) & $73.22 \pm 6.78$ & $67.23 \pm 7.31$ & $<0.001$ \\
\hline Gender [male, n (\%)] & $19(52.7 \%)$ & $69(46.6 \%)$ & 0.507 \\
\hline Hypertension [n (\%)] & $30(83.3 \%)$ & $109(73.6 \%)$ & 0.225 \\
\hline Diabetes mellitus [n (\%)] & $8(22.2 \%)$ & $25(16.8 \%)$ & 0.455 \\
\hline Hyperlipidemia [n (\%)] & $17(47.2 \%)$ & $48(32.4 \%)$ & 0.096 \\
\hline Coronary heart disease [n (\%)] & $8(15.7 \%)$ & $27(17.5 \%)$ & 0.585 \\
\hline Stroke $[\mathrm{n}(\%)]$ & $5(13.8 \%)$ & $15(10.1 \%)$ & 0.516 \\
\hline Systolic pressure & $154.61 \pm 24.18$ & $151.82 \pm 23.23$ & 0.522 \\
\hline Diastolic pressure & $78.76 \pm 14.40$ & $75.95 \pm 9.23$ & 0.149 \\
\hline Total cholesterol (mmol/L) & $5.31 \pm 0.98$ & $5.25 \pm 1.07$ & 0.760 \\
\hline Triglycerides (mmol/L) & $1.65 \pm 0.19$ & $1.53 \pm 0.41$ & 0.089 \\
\hline $\mathrm{HDL}-\mathrm{C}(\mathrm{mmol} / \mathrm{L})$ & $1.20 \pm 0.13$ & $1.17 \pm 0.12$ & 0.187 \\
\hline LDL-C (mmol/L) & $3.27 \pm 0.98$ & $3.35 \pm 1.04$ & 0.676 \\
\hline Blood glucose (mmol/L) & $5.40 \pm 1.75$ & $5.45 \pm 1.71$ & 0.876 \\
\hline $\mathrm{HbA} 1 \mathrm{C}(\mathrm{mmol} / \mathrm{L})$ & $5.50 \pm 1.32$ & $5.45 \pm 1.2$ & 0.826 \\
\hline Left MCA peak systolic velocity $(\mathrm{cm} / \mathrm{s})$ & $73.21 \pm 22.9$ & $77.01 \pm 22.03$ & 0.358 \\
\hline Left MCA mean flow velocity (cm/s) & $42.03 \pm 12.20$ & $49.58 \pm 12.67$ & 0.001 \\
\hline Right MCA peak systolic velocity (cm/s) & $74.01 \pm 24.21$ & $77.41 \pm 23.32$ & 0.437 \\
\hline Right MCA mean flow velocity (cm/s) & $43.64 \pm 12.83$ & $49.78 \pm 17.12$ & 0.045 \\
\hline Mean MCA pulsatility index (cm/s) & $1.15 \pm 0.23$ & $0.95 \pm 0.18$ & $<0.001$ \\
\hline
\end{tabular}

WMLs, white matter lesions; HDL-C: high-density lipoprotein cholesterol; LDL-C: low-density lipoprotein cholesterol; HbA1c: glycosylated hemoglobin; MCA: middle cerebral artery. 


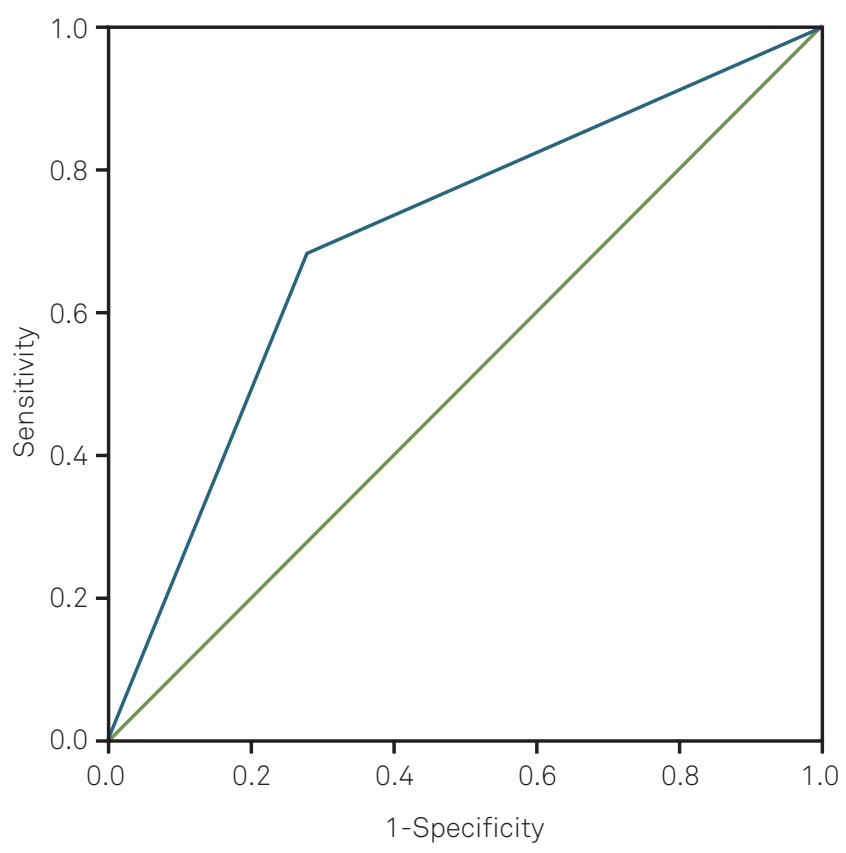

Figure. Receiver operating characteristic curves of the mean middle cerebral artery pulsatility index for predicting severe white matter lesions.

\section{Results of multivariate logistic regression analysis on factors related to severe WMLs}

As shown above, in univariate analysis, age, left MCA mean flow velocity, right MCA mean flow velocity and mean MCA pulsatility index were the variables significantly correlated with severe WMLs. Then, multivariate logistic regression analysis was performed on these variables. The results showed that only age (odds ratio: 1.21; $95 \%$ CI: 1.10-1.36; $\mathrm{p}<0.01$ ) and MCA pulsatility index (dominance ratio: 1.13; 95\% CI: $1.06-1.80 ; \mathrm{p}=0.02$ ) were significantly correlated with severe WMLs.

\section{Results of analysis on TCD ultrasound parameters}

Analysis of the TCD ultrasound parameters showed that when the cut-off of the mean MCA pulsatility index was $1.04 \mathrm{~cm} / \mathrm{s}$, this could identify whether the patients had severe WMLs or not. The area under the curve was 0.70 (95\% CI: 0.60-0.80). The sensitivity and specificity were $63.0 \%$ and $72.0 \%$, respectively. The positive predictive value and negative predictive value were $35.4 \%$ and $86.6 \%$, respectively (Figure).

\section{DISCUSSION}

Transcranial Doppler ultrasound is a technique that can noninvasively detect intracranial arterial lesions. It has the advantages of simple operation and strong repeatability. In addition, TCD ultrasound is economical and practical, and is easily tolerated by patients ${ }^{20}$. The TCD ultrasound is a reliable method for early diagnosis of intracranial arterial ischemic lesions, and can provide an objective hemodynamic basis for the selection of treatment methods for intracranial atherosclerotic lesions ${ }^{21}$. The pulsatility index is an important parameter of TCD ultrasound. It is primarily used to evaluate arterial compliance and elasticity, which reflect the changes of resistance in the cerebral blood vessels. The pulsatility index calculation formula is: (peak systolic velocity - end diastolic velocity) $\div$ mean flow velocity, from which a pulsatility index value increase shows the increase of cerebral vascular resistance, and a pulsatility index value decrease shows the decrease of cerebral vascular resistance. The increase in the pulsatility index is commonly found in hypertension, atherosclerosis, arterial stenosis, arterial spasm and intracranial hypertension, and its decrease is more common in an arteriovenous malformation ${ }^{22}$.

The results of this study showed that the MCA pulsatility index was significantly correlated with severe WMLs (dominance ratio: 1.13; 95\%CI: $1.06-1.80 ; \mathrm{p}=0.02$ ). When the cut-off of the mean MCA pulsatility index was $1.04 \mathrm{~cm} / \mathrm{s}$, whether the patients had severe WMLs or not, could be identified. The area under the curve was 0.70 (95\%CI: 0.60-0.80). The sensitivity and specificity were $63.0 \%$ and $72.0 \%$, respectively. The positive predictive value and negative predictive value were $35.4 \%$ and $86.6 \%$, respectively. At the best cut-off, although the positive predictive value was low, the negative predictive value was high. Therefore, the possibility of severe a WML was low for the patients with a normal MCA pulsatility index. In a study by Kim et al..$^{23}$, age and the brachial ankle pulse wave velocity were the independent determinants of the pulsatility index of MCAs in patients with a lacunar infarction. Mok et al..$^{24}$ found that the pulsatility index in TCD ultrasound correlated with WML severity. With a high negative predictive value, the chance of having severe WMLs with a normal pulsatility index was low. Results of a study by Ghorbani et al. ${ }^{15}$ showed that an increased TCD-derived pulsatility index could accurately indicate small vessel disease. The results of the present study are similar with those of the above studies. For the patients with subclinical cerebral small vessel disease, a TCD ultrasound can be used to guide a selective MRI scan only for patients with a high MCA pulsatility index. This can reduce the cost of examination and avoid the waste of unnecessary medical resources. In addition, this study did not find relevance of any other TCD ultrasound parameters with the severe WMLs.

The most obvious significance of this study is that it quantitatively analyzed the severity of WMLs. However, this study also had some limitations. Firstly, the sample sizes of patients with multiple lacunar infarctions and microhemorrhages were small. Therefore, the correlations of the MCA pulsatility index with lacunar infarctions and microhemorrhages still need to be studied further. Secondly, the data of the extracranial evaluations were not included. Thirdly, this study used the mean MCA pulsatility index value calculated from bilateral MCA pulsatility index values, which might reduce the difference between severe and non-severe 
small vessel disease patients. In future studies, the left and right MCA pulsatility index should be individually shown, to make the result more convincing. In conclusion, the MCA pulsatility index in TCD ultrasound is significantly correlated with severe WMLs. Application of a TCD ultrasound for diagnosing subclinical cerebral small vessel disease is still an important research direction. The TCD ultrasound technology is expected to become an important tool for the screening of cerebral small vessel disease, and has important clinical significance for evaluating WMLs.

\section{References}

1. Conijn MM, Kloppenborg RP, Algra A, Mali WP, Kappelle LJ, Vincken KL, et al.; SMART Study Group. Cerebral small vessel disease and risk of death, ischemic stroke, and cardiac complications in patients with atherosclerotic disease: the Second Manifestations of ARTerial disease-Magnetic Resonance (SMART-MR) study. Stroke. 2011 Nov;42(11):3105-9. https://doi.org/10.1161/STROKEAHA.110.594853

2. Mok VC, Wong A, Lam WW, Fan YH, Tang WK, KwokT, et al. Cognitive impairment and functional outcome after stroke associated with small vessel disease.J Neurol Neurosurg Psychiatry. 2004 Apr;75(4):560-6. https://doi.org/10.1136/jnnp.2003.015107

3. van der Flier WM, van Straaten EC, Barkhof F, Verdelho A, Madureira S, Pantoni L, et al. Small vessel disease and general cognitive function in nondisabled elderly: the LADIS study. Stroke. 2005 Oct;36(10):2116-20. https://doi.org/10.1161/01.STR.0000179092.59909.42

4. Kalaria RN. Small vessel disease and Alzheimer's dementia: pathological considerations. Cerebrovasc Dis. 2002;13 Suppl 2:4852. https://doi.org/10.1159/000049150

5. de Laat KF, Tuladhar AM, van Norden AG, Norris DG, Zwiers MP, de Leeuw FE. Loss of white matter integrity is associated with gait disorders in cerebral small vessel disease. Brain. 2011 Jan;134(Pt 1):73-83. https://doi.org/10.1093/brain/awq343

6. Patel B, Markus HS. Magnetic resonance imaging in cerebral small vessel disease and its use as a surrogate disease marker. Int J Stroke. 2011 Feb;6(1):47-59. https://doi.org/10.1111/j.1747-4949.2010.00552.x

7. Dearborn JL, Schneider AL, Sharrett AR, Mosley TH, Bezerra DC, Knopman DS, et al. Obesity, insulin resistance, and incident small vessel disease on magnetic resonance imaging: atherosclerosis risk in communities study. Stroke. 2015 Nov;46(11):3131-6. https://doi.org/10.1161/STROKEAHA.115.010060

8. Boulouis G, Etten ES, Charidimou A, Auriel E, Morotti A, Pasi $M$, et al. Association of key magnetic resonance imaging markers of cerebral small vessel disease with hematoma volume and expansion in patients with lobar and deep intracerebral hemorrhage. JAMA Neurol 2016 Dec;73(12):1440-7. https://doi.org/10.1001/jamaneurol.2016.2619

9. Schmidt R, Scheltens P, Erkinjuntti T, Pantoni L, Markus HS, Wallin A, et al. White matter lesion progression: a surrogate endpoint for trials in cerebral smallvessel disease. Neurology. 2004 Jul;63(1):139-44. https://doi.org/10.1212/01.WNL.0000132635.75819.E5

10. Adachi T, Kobayashi S, Yamaguchi S, Okada K. MRI findings of small subcortical "lacunar-like" infarction resulting from large vessel disease. J Neurol. 2000 Apr;247(4):280-5. https://doi.org/10.1007/s004150050584

11. Roob G, Schmidt R, Kapeller P, Lechner A, Hartung HP, Fazekas F. MRI evidence of past cerebral microbleeds in a healthy elderly population. Neurology. 1999 Mar;52(5):991-4. https://doi.org/10.1212/WNL.52.5.991

12. Chen J, Wang L, Bai J, Lun Z, Zhang J, Xing Y. The optimal velocity criterion in the diagnosis of unilateral middle cerebral artery stenosis by transcranial Doppler. Cell Biochem Biophys. 2014 May;69(1):81-7. https://doi.org/10.1007/s12013-013-9771-9
13. Shim Y, Yoon B, Shim DS, Kim W, An JY, Yang DW. Cognitive correlates of cerebral vasoreactivity on transcranial Doppler in older adults. J Stroke Cerebrovasc Dis. 2015 Jun;24(6):1262-9. https://doi.org/10.1016/j.jstrokecerebrovasdis.2015.01.031

14. Levin JH, Benavides J, Caddick C, Laurie K, Wilterdink J, Yaghi S, et al. Transcranial doppler ultrasonography as a non-invasive tool for diagnosis and monitoring of reversible cerebral vasoconstriction syndrome. R I Med J (2013). 2016 Sep;99(9):38-41.

15. Ghorbani A, Ahmadi MJ, Shemshaki H. The value of transcranial Doppler derived pulsatility index for diagnosing cerebral small-vessel disease. Adv Biomed Res. 2015 Feb;4(1):54. https://doi.org/10.4103/2277-9175.151574

16. Kidwell CS, el-Saden S, Livshits Z, Martin NA, Glenn TC, Saver JL. Transcranial Doppler pulsatility indices as a measure of diffuse small-vessel disease. J Neuroimaging. 2001 Jul;11(3):229-35. https://doi.org/10.1111/j.1552-6569.2001.tb00039.x

17. Martí-Fàbregas J, Belvís R, Guardia E, Cocho D, Muñoz J, Marruecos $L$, et al. Prognostic value of Pulsatility Index in acute intracerebral hemorrhage. Neurology. 2003 Oct;61(8):1051-6. https://doi.org/10.1212/01.WNL.0000090520.67254.14

18. Team of Chinese Expert Consensus on the Diagnosis and Treatment of Cerebral Small Vessel Disease. Chinese expert consensus on the diagnosis and treatment of cerebral small vessel disease. Chin J Integr Med. 2013;52:893-6. Chinese.

19. Olsson E, Klasson N, Berge J, Eckerström C, Edman A, Malmgren $\mathrm{H}$, et al. White matter lesion assessment in patients with cognitive impairment and healthy controls: reliability comparisons between visual rating, a manual, and an automatic volumetrical MRI method-the Gothenburg MCl study. J Aging Res. 2013;2013:198471. https://doi.org/10.1155/2013/198471

20. Demolis P, Chalon S, Giudicelli JF. Repeatability of transcranial Doppler measurements of arterial blood flow velocities in healthy subjects. Clin Sci (Lond). 1993 Jun;84(6):599-604. https://doi.org/10.1042/cs0840599

21. Liu Z, Zhou Y, Yi R, He J, Yang Y, Luo L, et al. Quantitative research into the deconditioning of hemodynamic to disorder of consciousness carried out using transcranial Doppler ultrasonography and photoplethysmography obtained via fingertransmissive absorption. Neurol Sci. 2016 Apr;37(4):547-55. https://doi.org/10.1007/s10072-015-2429-1

22. Mone F, Thompson A, Stewart MC, Ong S, Shields MD. Fetal umbilical artery Doppler pulsatility index as a predictor of cardiovascular risk factors in children: a long-term follow up study. J Matern Fetal Neonatal Med. 2014 Nov;27(16):1633-6. https://doi.org/10.3109/14767058.2013.871698

23. Kim DH, Choi JH, Moon JS, Kim HJ, Cha JK. Association between the severity of cerebral small vessel disease, pulsatility of cerebral arteries, and brachial ankle pulse wave velocity in patients with lacunar infarction. Eur Neurol. 2010;64(4):247-52. https://doi.org/10.1159/000319923

24. Mok V, Ding D, Fu J, Xiong Y, Chu WW, Wang D, et al. Transcranial Doppler ultrasound for screening cerebral small vessel disease: a community study. Stroke. 2012 Oct;43(10):2791-3. https://doi.org/10.1161/STROKEAHA.112.665711 